\title{
THE PSYCHOLOGICAL IMPACT OF CHANGING HABITS IN CONTEMPORARY COMMUNICATION ON EDUCATION PROCESSES
}

\author{
Inguna Griskevica \\ Rīga Stradiņš University, Faculty of Public Health and Social Welfare, Department of Health \\ Psychology \\ Liepaja University Institute of Educational Sciences, Latvia
}

\begin{abstract}
Education is beginning to undergo enormous change due to changes in communication habits driven by the widespread availability of digital technology. Research has found significant differences between generations that recently inhabited our society in relationships with digital communication. This semi-structured qualitative pilot study was designed as research to determine what differences existed between generations in education settings surrounding their preferred communication methods. The research for this study framed around the following three questions: (a) Are there differences in preferred methods of communication-based on generational classification? (b) Is there any difference in the use of technology as a socialization instrument between generations? (c) Is there a difference in the perceived quality of intermediate and indirect communication? A focused semi-structured interview created to determine how much of the daytime different generations spend on intermediate and indirect communication and how the quality is perceived. The results of the study from 450 samples from three generations demonstrate differences between the students and teacher perception of communication.
\end{abstract}

Keywords: communication, generation, technology.

\section{Introduction}

The new technologies are now changing not only the role of the learner and the teacher at school, but they also bring about a philosophical change in the teaching approach, transform the classroom and understanding what the education is. When we look at new schools, we can see that the similarities with the traditional school are slowly fading. Much has changed with the advent of modern technology. Although students and teachers use different modern technologies like the Internet and gadgets, research has found meaningful differences between generations in changing habits of contemporary technology-driven communication with the psychological impact on education processes (Oh \& Reeves, 2013). Teachers complain that modern students are so accustomed to constant stimuli from smartphone apps and streaming platforms, that they cannot concentrate on class tasks. Teachers often have problems, how to adapt the 
traditional curriculum to students raised by technology, and how to communicate with them (Murugesan, 2019). Although the face-to-face interaction with the teacher is still the most critical component in the classroom, the modern communication forms on platforms like YouTube and Instagram more and more introduced in the education process. There is no doubt that our society is moving much faster than in previous years and often children enter the school system with a better understanding of technology than teachers who may result in conflict between generations (Smith, 2006). The differences between generations may set up some unique and sometimes conflicting situations in the education of youth. For example, Boomer parents and Generation, $\mathrm{X}$ parents have opposing views concerning the education of our children. Generation of Baby Boomers is likely to support education as a social or symbolic cause, while Generation X members will demand the best education for their children (Strauss 2005).

Research has found that generational groups have created their social structure and set of cultural norms that define each generation. One of the unique differences among these generations is the methods they use to communicate (Craft, 2011; Howe \& Strauss, 2007). Predominant theories agree that differences exist between generations and that generational cohorts react to each other based on events that have occurred and shaped their lives (Howe \& Strauss, 2007). With the technologies present today, the use of face-to-face communication is being replaced by the speed of technology to communicate. The Generation Baby Boomers were born in the adoption of the telephone and were the first generation to experience live news over the television. Generation $\mathrm{X}$ was born into the adoption era of the Internet and email when the length of conversations became shorter, but the number of contacts grew larger. Generation $\mathrm{Z}$ is supposed to be the first generation of true digital natives.

Studies show that today's young people have access to unbelievably more technology than ever before. Young people prefer to use the Internet for computer games, correspondence and social networking. In America, 92\% of young people use the Internet every day, and $24 \%$ of young people spend almost all their time on the Internet. On average, in America, young people between the ages of eight and 18 spend an average of 7 hours online (AAP, 2016). Studies show that today's children are familiar with digital devices ahead of books, and trends indicate an increase in their use (Hooft, 2018; Hopkins, Brookes, \& Green, 2013). Many tried to attract the popularity of technologies to the development of the child's mental health and well-being. There is a lack of research on the impact of technology on children under the age of eight (Gottschalk, 2019). In recent years, there has been much research exploring the possible links between emotional well-being, mental health and the use of technology in children, particularly concerning brain effects, but these results are unclear (Bavelier, Green, \& Dye, 2010; Gottschalk, 2019). Studies often associate the excessive use of technology with inadequate physical 
fitness, inadequate behavioural standards, low levels of attention, and psychological problems (Rosen et al., 2014). There is more research on the impact of television on children's speech, cognitive, physical, and emotional development due to the relatively long history of television (Gottschalk, 2019). The studies linked TV with attention-retention problems (Christakis et al., 2004). In a repeated study showed that $10 \%$ of children watching TV for 7 hours per day showed to have attention deficit problems and no significant relationship found between watching TV and duration of attention (Foster \& Watkins, 2010). Some studies link television viewing to the development of literacy, mathematical, problemsolving, and scientific skills, as well as the promotion of social development in preschool children (Schmidt \& Anderson, 2009).

Despite the lack of impact studies, many countries have developed technology guidelines that more often based on prohibition or restriction principles. The American Pediatric Association (AAP, 2016) has developed technology restriction guidelines that advise children under 18 months not to use the technology at all, and allow children under the age of five to use the technology 1 hour per day. The recommended screen time in countries like the US, Canada, Australia is 2 hours for school-age children and adolescents, and in New Zealand for 1 hour, in Germany 30 minutes (Gottschalk, 2019). For example, Google does not allow children and young people to view the YouTube channel until the age of 13 on their phones. In 2019, the Royal College of Pediatrics and Child Health (RCPCH) published a guide for parents and professionals to help limit technology use time. The RCPCH concluded that there is not enough research to prove that technology is harmful to a child, regardless of age. Some research cites a potential "Goldilocks effect" in terms of technology use. Research suggests that moderate engagement in online and digital activities might be beneficial in terms of subjective mental well-being and adolescent connectedness. Thus too much or too little digital activities might be detrimental (Przybylskiand \& Weinstein, 2017).

The goal of this study is to state the differences in preferred methods of communication-based on generational classification between three generations. Most typically inhabited in Latvia regional school environment: Baby Boomers (Gen B) which is born ones between 1946 and 1964, Generation X (Gen X) who are born ones between 1965 and 1980 and Generation Z (Gen Z) which are born ones between 1996 and 2010. Data demonstrate (TALIS, 2018) that average age for teachers in Latvia is 48, more than half, $51 \%$ - are more than 50 years old, average for school directors is age 54 from which $25 \%$ are more than 60 years old, $89 \%$ of teachers are female. The purpose of this study was to determine whether generational differences existed in the way each generation uses technology for communication. We created a survey interview instrument to test the difference in the use of communication methods by each generation. 
Griskevica, 2020. The Psychological Impact of Changing Habits in Contemporary

Communication on Education Processes

\section{Methodology}

\section{Participants}

The study conducted in the frame of a communication course for university students who study to become teachers. The random sampling used with representatives from regional schools in Latvia according to demographic distribution data of gender proportion of teachers (TALIS, 2018). The variable of generations created by coding respondents born between 1954 to 1963 as Gen B, 1964 to 1974 as Gen X, and 2003 to 2005 as Gen Z. Students from Gen Z, $N=150$, age 14 to $16(M=15.02, S D=0.91,50 \%$ male), teachers from Gen $\mathrm{X}, N=150$, age 45 to $55(M=50.44, S D=2.92,11 \%$ male), teachers from Gen B, $N=150$, age 56 to $65(M=60.23, S D=1.81,11 \%$ male) were selected.

\section{Instrument}

A focused semi-structured interview created to determine how much of the daytime different generations spend on a face-to face communication versus technology-mediated indirect communication and how the quality of the communication process is perceived. The following question included: (a) how much time on communication spent; (b) what are the types of communication; (c) what means of communication are used in direct face-to-face or indirect (Technology mediated communication.); (d) how the quality of communication is perceived. Intraclass Correlation Coefficient (ICC=.90) and Kappa $(\mathrm{k}=.71)$ values for inter-rater reliability were tested and showed good agreement for the instrument. The reliability analysis concluded that the reliability of each question when compared as a whole, yielded reliability ranging from substantial to almost perfect.

\section{Procedure and Data Analyses}

Participants recruited in the frame of a communication course for university students who study to become teachers. Data were obtained individually by students interviewing each participant separately. Before the interview, the aims of the study explained, and the ethical aspects of elucidated. Participation was voluntary. Coding respondents created the variables according to generational classification compared to three stated research questions: (a) Are there differences in preferred methods of communication-based on generational classification? (b) Is there any difference in the use of technology as a socialization instrument between generations? (c) Is there a difference in the perceived quality of intermediate and indirect communication? SPSS program used and Chi-Square analysis conducted. 


\section{Research results}

To answer the question is their differences in preferred methods of communications-based on generational classification, we conducted a Chi-Square analysis. The generational classification compared to question on the most preferred method of communication and significant relationship found between generation and most preferred method of communication, $\chi^{2}(4, N=450)=8.9$, $\mathrm{p}<.001$. The results are shown in Table 1 .

To answer the question is there any difference in the generation's use of technology as a socialization instrument, we conducted a Chi-Square analysis. The generational classification compared to question on most used types of communication and significant relationship found between generation and most used types of communication, $\chi^{2}(6, N=450)=9.2, \mathrm{p}<.001$. The results are shown in Table 2.

To answer the question is there a difference in the perceived quality of intermediate and indirect communication, we conducted a Chi-Square analysis. The generational classification compared to the evaluation of the perceived quality of communication and we found no significant relationship between generation and evaluation of the perceived quality of communication, $\chi^{2}$ $(4, N=450)=1.7, \mathrm{p}>.05$. The results show Table 3 .

Table 1 Generation and Most Preferred Communication

\begin{tabular}{|l|c|c|c|}
\hline Generation & $N$ & \multicolumn{2}{|c|}{ Most Preferred Communication } \\
\hline & & Face To Face & Technology-Mediated \\
\hline Gen B & 150 & $81.6 \%$ & $18.4 \%$ \\
\hline Gen X & 150 & $62.4 \%$ & $37.6 \%$ \\
\hline Gen Z & 150 & $40.3 \%$ & $59.7 \%$ \\
\hline
\end{tabular}

Note. Percentages calculated by row

Table 2 Generation and Most Used Type of Communication

\begin{tabular}{|l|c|c|c|c|}
\hline Generation & $N$ & \multicolumn{3}{|c|}{ Most Used Type of Communication } \\
\hline & & Personal & Business & Ritual \\
\hline Gen B & 150 & $43.3 \%$ & $30.6 \%$ & $26.1 \%$ \\
\hline Gen X & 150 & $32.2 \%$ & $42.3 \%$ & $25.5 \%$ \\
\hline Gen Z & 150 & $75.4 \%$ & $14.2 \%$ & $10.4 \%$ \\
\hline
\end{tabular}

Note. Percentages calculated by row 
Griskevica, 2020. The Psychological Impact of Changing Habits in Contemporary Communication on Education Processes

Table 3 Generation and Perceived Quality of Communication

\begin{tabular}{|l|c|c|c|}
\hline Generation & $N$ & \multicolumn{2}{|c|}{ Communication Type } \\
\hline & & Intermediate & Indirect \\
\hline Gen B & 150 & 8.2 & 5.7 \\
\hline Gen X & 150 & 7.9 & 6.6 \\
\hline Gen Z & 150 & 7.5 & 7.4 \\
\hline
\end{tabular}

Note. Average rating between 1-10

\section{Discussion}

The goal of this study was to state the differences in preferred methods of communication-based on generational classification between tree generations Gen B, Gen X and Gen Z, determine whether generational differences existed in the way each generation uses technology for communication. Three research questions were asked according to the differences in preferred methods of communication, the difference in the use of technology as a socialization instrument and the difference in the perceived quality of intermediate and indirect communication. The results of our semi-structured qualitative pilot study suggest that differences in preferred methods of communication-based on generational classification between Gen B, Gen X and Gen Z exist. Gen Z prefers more technology-mediated communication versus Gen $B$ and Gen $X$, who prefer more face to face communication. The qualitative analyses of the results reveal differences between Gen B, Gen X and Gen Z in the way they use technology as the socialization instrument. Gen $\mathrm{Z}$ preferred face-to-face communication more in business settings but technology-mediated communication in personal settings.

In contrast, Gen B and Gen X revealed the opposite tendency: to use face to face communication in personal settings, but technology-mediated communication in business settings. Outstandingly data demonstrate differences in the types of communication during a typical day between generations. Gen Z most of the communication time use on personal communication and often classroom time, did not recognize as any type of communication, which may be an essential signal for education process organizers. Data analyses reveal trendsas the more younger generation, as lower evaluated the perceived quality of the intermediated communication and higher indirect communication. Overall results demonstrate no significant differences in the perceived quality of intermediated or indirect communication between generations, which challenges the myth between older generations, that the younger generation due to technologymediated communication may suffer from poor communication processes or skills. The study revealed generational differences in perception of technology and communication process similar to other research data which note the possible 
conflict between generations (Smith, 2006; Murugesan, 2019), starting from expectation disagreements (Griskevica, 2017) and opposing views concerning the educational aims and education processes (Strauss, 2005).

\section{Conclusions}

Any progressive school will agree that confining Gen $\mathrm{Z}$ to the regimented classroom and chalk-and-talk teaching will lead to futile learning. To keep up with the present generation's learning style, schools have to leverage on technology and different communication style with students. Recent analyses of research data concerning technology impact on development, mental health, well-being and communication skills demonstrate conflicting results and are unclear (Gottschalk, 2019). This pilot study addressed only a small sample of the population and showed just a few prevailing tendencies, but additional research with the larger sample is necessary.

\section{References}

AAP. (2016). American Academy of Pediatrics Announces New Recommendations for Children's Media Use. Retrieved from https://www.aap.org/en-us/about-the-aap/aappress-room

Bavelier, D., Green, C.S., \& Dye, M.W.G. (2010). Children, Wired: For Better and for Worse. Neuron, 67(5), 692-701.

Christakis, D.A., Zimmerman, F.J., DiGiuseppe, D.L., \& McCarty, C.A. (2004). Early Television Exposure and Subsequent Attentional Problems in Children. Paediatrics, 113(4), 708-13.

Craft, T.E.J. (2011). Understanding Inter-and Intra-Generational Communication Methods Utilizing a Framework of Message Sensitivity. Dissertations, Paper 8. Retrieved from https://digitalcommons.wku.edu/diss/8

Foster, E., \& Watkins, S. (2010). The Value of Reanalysis: TV Viewing and Attention Problems. Child Development, 81(1), 368-375.

Gottschalk, F. (2019). Impacts of Technology Use on Children: Exploring Literature on the Brain, Cognition and Well-Being. OECD Education Working Papers, 195. OECD Publishing

Griskevica, I. (2017). Psychological Traits in Teacher and Pupil Mutual Communication. 3rd International Conference on Lifelong Education and Leadership for All (ICLEL). Book of Conference Proceedings, 41-51.

Hooft, G.J. (2018). New technologies and 21st-century children: Recent trends and outcomes. OECD Education Working Papers, 179, OECD Publishing.

Hopkins, L., Brookes, F., \& Green, J. (2013). Books, bytes and brains: The implications of new knowledge for children's early literacy learning. Australasian Journal of early childhood, 38(1), 23-2.

Howe, N., \& Strauss, W. (2000). Millennials are rising. New York: Random House. 
Griskevica, 2020. The Psychological Impact of Changing Habits in Contemporary

Communication on Education Processes

Murugesan, V. (2019). Modern Teaching Techniques in Education. Educational Technology in Teacher Education in the 21st Century, At Government College of Education for Women, Coimbatore, Conference Paper.

Rosen, L.D., Lim, A.F., Felt, J., Carrier, L.M., Cheever, N.A., Lara-Ruiz, J.M., ... \& Rokkum, J. (2014). Media and technology use predicts ill-being among children, preteens and teenagers independent of the negative health impacts of exercise and eating habits. Computers in human behavior, 35, 364-375.

Schmidt, M.E., \& Anderson, D.R. (2007). The Impact of Television on Cognitive Development and Educational Achievement. In N. Pecora, J.P. Murray, \& E.A. Wartella (Eds.), LEA's communication series. Children and television: Fifty years of research (pp. 65-84). Erlbaum, Mahwah, NJ: Lawrence Erlbaum Associates Publishers.

Smith, D.C. (2006). Educating the millennial student: Some challenges for academics. Proceedings of the 2006 SACLA Conference. Cape Town: University of Cape Town. Strauss, W.(2003). Millennials go to college - American Association of Collegiate Registrars and Admissions Offices, 1-4.

Strauss, W.(2005). Making sense of a school environment made of gen-Xers and millennials. School Administrator, 10-14.

Przybylski, A., \& Weinstein, N. (2017). A Large-Scale Test of the Goldilocks Hypothesis. Psychological Science, 28(2), 204-215.

RCPCH. (2019). The health impacts of screen time: a guide for clinicians and parents. Royal College of Paediatrics and Child Health, London, United Kingdom.

Oh, E.G., \& Reeves, T.C. (2013). Generational Differences and the Integration of Technology in Learning, Instruction, and Performance. In J. Michael Spector, M. David Merrill, Jan Elen, M.J. Bish (Eds.), Handbook of Research on Educational Communications and Technology (pp. 819-828). Springer.

TALIS. (2018). Teaching and Learning International Survey. Teachers and School Leaders as Lifelong Learners, Results, Volume I, OECD publishing. 